Supporting Information

\title{
Isotopic Analysis by Laser Ablation Solution Sampling MC- ICP-MS-An Example of Boron
}

\author{
Xiuhong Liao, Zhaochu Hu*, Wen Zhang, Yantong Feng, Tao Luo, Zaicong \\ Wang, Ming Li, Keqing Zong, Yongsheng Liu, and Shenghong Hu
}

State Key Laboratory of Geological Processes and Mineral Resources, China University of Geosciences, Wuhan, 430074, PR China

*Author to whom correspondence should be sent.

Email: zchu@vip.sina.com,Tel.: +862761055600,Fax: +86 27678850 


\section{Outline}

The detailed procedure of geological material digestion process is provided in Section S-1. Boron recovery measurement process is described in Section S-2, and the results are shown in Table S-1. Time-resolved B signals produced by laser ablation solution sampling MC-ICP-MS in the standard NIST 951a solution is shown in Figure S-1. Memory effect illustrated by ${ }^{11} \mathrm{~B}$ signal versus time measured by LA-MC-ICP-MS after the NIST 951a solution and NIST 610 glass being ablated for $50 \mathrm{~s}$ is shown in Figure S-2. 


\section{S-1: Geological material digestion process}

The digestion process mainly was carried out according to Zhang et al. ${ }^{1}$ but with a few minor modifications:

(1) $300 \mathrm{mg}$ of $\mathrm{NH}_{4} \mathrm{HF}_{2}(\mathrm{AR}, 98.5 \%$ metals basis) powder and $50 \mathrm{mg}$ of geological reference material powder (IAEA-B6 and B8 in this research) were weighted into a 15-mL screw-top PFA vial;

(2) The vails were then capped and heated at $230{ }^{\circ} \mathrm{C}$ in an electric oven for $3 \mathrm{~h}$;

(3) After cooling, $2 \mathrm{~mL}$ of $\mathrm{HNO}_{3}$ was added, and the vials were capped and placed on a hot plate at $120^{\circ} \mathrm{C}$. After $1 \mathrm{~h}$, the vials were opened and evaporated to near dryness at $120^{\circ} \mathrm{C}$ on the hot plate;

(4) The residue was then dissolved in $5 \%(\mathrm{v} / \mathrm{v}) \mathrm{NH}_{3} \cdot \mathrm{H}_{2} \mathrm{O}$ to a final weight of $5 \mathrm{~g}$ (transferred to a polyethylene tube);

(5) After standing for $12 \mathrm{~h}$, the sample was centrifuged for $15 \mathrm{~min}$ at $4000 \mathrm{rpm}$. Then, $2 \mathrm{~mL}$ of the supernatant was transferred and stored in a polyethylene tube for quantitative boron recovery and isotopic analysis. 


\section{S-2: Boron recovery measurement}

Boron recoveries in the supernatant solution of the digested samples were determined by an Agilent 7900 ICP-MS (Agilent Technologies, Tokyo, Japan) with laser ablation introduction system following the method detailed in Liao et al., ${ }^{2}$ using NIST 610 as the external calibrator and indium as the internal standard. For each sample, $1 \mathrm{~mL}$ of the supernatant solution was placed into a polyethylene tube, and $100 \mu \mathrm{L}$ of indium standard solution $\left(1 \mu \mathrm{g} \mathrm{mL}^{-1}\right)$ was added as the internal standard. The measured boron content was $209.9 \pm 4.3 \mu \mathrm{g} \mathrm{g}^{-1}(\mathrm{n}=8)$ in IAEA-B6 and 100.2 $\pm 3.3 \mu \mathrm{g} \mathrm{g}^{-1}(\mathrm{n}=8)$ in IAEA-B8, with recoveries of approximately 100\% (Table S-1). This demonstrated that B volatilization did not occur during the digestion procedure.

Table S-1. The determined results of B concentration in the supernatants of digested geological materials.

\begin{tabular}{cccccc}
\hline Sample & $\begin{array}{c}\text { Concentration } \\
\left(\mu \mathrm{g} \mathrm{g}^{-1}\right)\end{array}$ & $\begin{array}{c}\text { Mean value } \\
\left(\mu \mathrm{g} \mathrm{g}^{-1}\right)\end{array}$ & $\begin{array}{c}\text { std. deviation } \\
\left(\mu \mathrm{g} \mathrm{g}^{-1}\right)\end{array}$ & $\begin{array}{c}\text { Ref. conc. } \\
\left(\mu \mathrm{g} \mathrm{g}^{-1}\right)\end{array}$ & $\begin{array}{c}\text { Recovery } \\
(\%)\end{array}$ \\
\cline { 2 - 6 } IAEA-B6 & $204.8,204.4,205.7,212.0$, & 209.9 & 4.3 & $205.8^{3}$ & 102 \\
$\begin{array}{c}\text { (Obsidian) } \\
\text { IAEA-B8 } \\
(\text { Clay })\end{array}$ & $\begin{array}{l}212.4,213.3,211.7,215.7 \\
100.0,93.3,103.7,102.3,\end{array}$ & 100.2 & 3.3 & $98.8^{4}$ & 101 \\
\hline
\end{tabular}




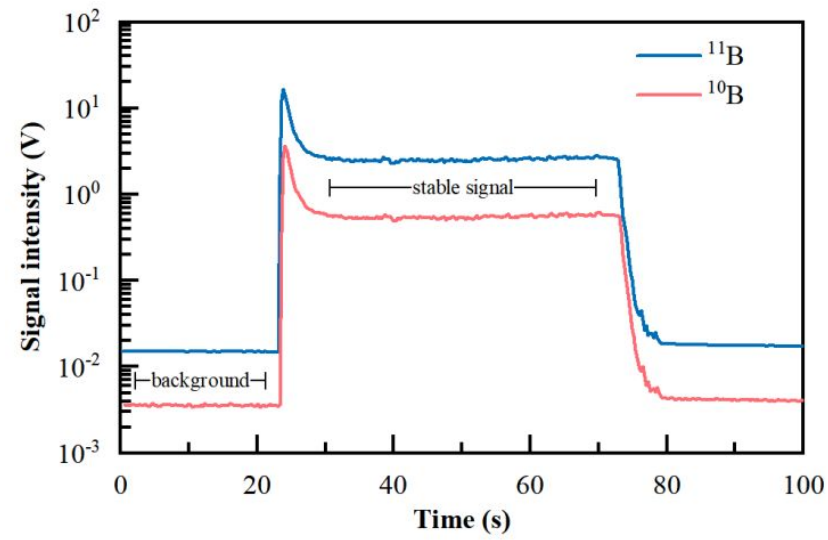

Figure S-1. Time-resolved B signals produced by laser ablation solution sampling MCICP-MS in the standard NIST 951a solution $\left(10 \mu \mathrm{g} \mathrm{mL}-1,5 \% \mathrm{NH}_{3} \cdot \mathrm{H}_{2} \mathrm{O}\right)$. 


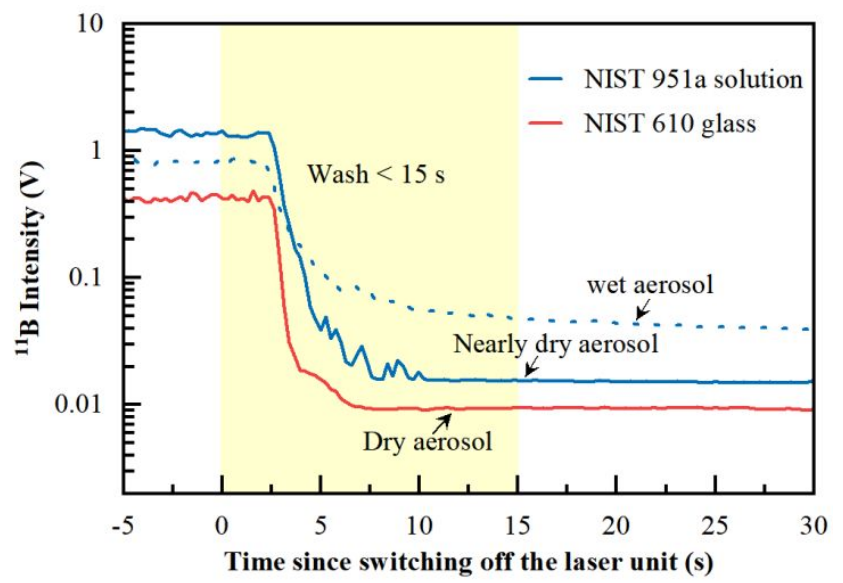

Figure S-2. ${ }^{11}$ B signal versus time measured by LA-MC-ICP-MS after the NIST 951a solution (solid blue line) and NIST 610 glass (red line) were ablated for $50 \mathrm{~s}$. The ${ }^{11} \mathrm{~B}$ signal under "wet" plasma condition (blue dashed line, with water nebulized into MCICP-MS during laser ablation of the NIST 951a solution sample) is also presented for comparison.

\section{REFERENCES:}

(1) Zhang, W.; Hu, Z. C.; Liu, Y. S.; Chen, H. H.; Gao, S.; Gaschnig, R. M. Total Rock Dissolution Using Ammonium Bifluoride $\left(\mathrm{NH}_{4} \mathrm{HF}_{2}\right)$ in Screw-Top Teflon Vials: A New Development in Open-Vessel Digestion. Anal. Chem. 2012, 84, 10686-10693.

(2) Liao, X. H.; Hu, Z. C.; Luo, T.; Zhang, W.; Liu, Y. S.; Zong, K. Q.; Zhou, L.; Zhang, J. F. Determination of Major and Trace Elements in Geological Samples by Laser Ablation Solution Sampling-Inductively Coupled Plasma Mass Spectrometry. J. Anal. At. Spectrom. 2019, 34, 1126-1134.

(3) Tonarini, S.; Pennisi, M.; Adorni-Braccesi, A.; Dini, A.; Ferrara, G.; Gonfiantini, R.; Wiedenbeck, M.; Gröning, M. Intercomparison of Boron Isotope and Concentration Measurements. Part I: Selection, Preparation and Homogeneity Tests of the Intercomparison Materials. Geostand. Newslett. 2003, 27, 21-39.

(4) Pi, J.-1.; You, C.-F.; Chung, C.-H. Micro-Sublimation Separation of Boron in Rock Samples for Isotopic Measurement by MC-ICPMS. J. Anal. At. Spectrom. 2014, 29, 861-867. 